\title{
Observations on the Factors that Control the Generation of Triiodothyronine from Thyroxine in Rat Liver and the Nature of the Defect Induced by Fasting
}

\author{
Alan Balsam and Sidney H. IngBar with the technical assistance of FrankLin \\ Sexton, Thorndike Laboratory, Harvard Medical School, and Department of \\ Medicine, Beth Israel Hospital, Boston, Massachusetts 02215
}

A B S T RAC T Studies were performed to explore the mechanism underlying the impaired generation of ${ }^{125}$-I-3,5,3'-triiodothyronine $\left(\mathrm{T}_{3}\right)$ from ${ }^{125}$ I-thyroxine $\left(\mathrm{T}_{4}\right)\left(\mathrm{T}_{3}\right.$-neogenesis) in preparations of liver from rats fasted for $48 \mathrm{~h}$ and the prevention of this effect by the feeding of glucose. $\mathrm{T}_{3}$-neogenesis in livers from fasted animals and those fed chow or glucose was assessed in various mixtures of crude microsomal fractions with either buffer or cytosols. $T_{3}$-neogenesis was mediated by an enzyme present in the microsomal fraction whose activity was enhanced by cytosolic cofactor(s). In livers from animals fasted for $48 \mathrm{~h}$, the supporting activity of cytosol was decreased, whereas the activity of the enzyme was unaffected. Administration of glucose as the sole nutritional source prevented the decrease in the supporting activity of hepatic cytosol that was regularly observed in the case of animals totally deprived of food.

The diminished supporting activity for $\mathrm{T}_{3}$-neogenesis provided by liver cytosol from fasted animals was restored to normal by enrichment with either NADPH or GSH, but the two cofactors appeared to act at different loci. GSH stimulated $\mathrm{T}_{3}$-neogenesis in microsomes incubated in the absence of cytosol, i.e., in buffer, whereas NADPH did not. The stimulatory effect of both agents was blocked by the sulfhydryl oxidant, diamide, which also inhibited $\mathrm{T}_{3}$-neogenesis in mixtures of microsomes with cytosols. Taken together, these observations suggest that GSH acts directly on the enzyme in the crude microsomal fraction, whereas NADPH acts within the cytosol, possibly by increasing the concentration of GSH through the action of the enzyme glutathione reductase, for which NADPH is a cofactor. In this light, the decreased supporting activity of hepatic cytosol

Received for publication 26 October 1978 and in revised form 12 February 197.9. from starved animals appears to reflect, at least partly, a decreased concentration of one or both cofactors.

The direct stimulation of enzyme activity by GSH, and the apparent lack of inhibition of unstimulated activity by diamide, suggests that the 5 -monodeiodinase for thyroxine that mediates $T_{3}$-neogenesis may be a GSH transhydrogenase.

\section{INTRODUCTION}

The demonstration that $3,5,3^{\prime}$-triiodothyronine $\left(T_{3}\right)^{1}$ is produced in the peripheral tissues of man by monodeiodination of thyroxine $\left(\mathrm{T}_{4}\right)$ in its outer ring has rekindled an intense interest in the deiodinative metabolism of the thyroid hormones and their metabolites (1-4). In man, it has become clear that approximately one-third of the metabolism of $\mathrm{T}_{4}$ proceeds along a pathway that leads initially to the formation of $T_{3}(2-4)$; that in normal individuals peripheral conversion of $\mathrm{T}_{4}$, rather than thyroid secretion, accounts for most or nearly all of $T_{3}$ production (2-4); and that a major portion of the metabolic activity evoked by $T_{4}$ may be attributed to its conversion to $T_{3}$. It has also become apparent that the peripheral metabolism of $\mathrm{T}_{4}$ can traverse an alternate pathway, in which the hormone is monodeiodinated in its inner ring to yield $3,3^{\prime}, 5^{\prime}-\mathrm{T}_{3}$ or reverse $T_{3}(5)$, a product generally considered to have virtually no hormonal activity $(6,7)$.

In man, a variety of influences lower the serum $T_{3}$ concentration. These include fasting or partial caloric deprivation (8-12); diabetes (13-15); surgical stress $(16,17)$; moderate or severe chronic illness $(18-20)$; cirrhosis $(21,22)$; and a number of drugs, including

\footnotetext{
${ }^{1}$ Abbreviations used in this paper: $\mathrm{I}^{-}$, iodide; $\mathrm{T}_{3}, 3,5,3^{\prime}$ triiodothyronine; $\mathrm{T}_{4}$, thyroxine; $\mathrm{T}_{3}$-neogenesis, generation of $\mathrm{T}_{3}$ from $\mathrm{T}_{4}$.
} 
propylthiouracil $(23,24)$, glucocorticoids in high doses $(25-27)$, certain radiographic contrast media $(28,29)$, and the beta adrenergic blocking agents, propranolol (30) and amiodarone (31). It has generally been assumed that all of these factors act primarily to decrease production of $T_{3}$ from $T_{4}$, rather than to increase peripheral degradation of $\mathrm{T}_{3}$, and direct studies have shown this to be true in the case of cirrhosis $(5,22)$, fasting $(12,32)$, and diabetes (15).

In previous studies we have demonstrated that the conversion of $T_{4}$ to $T_{3}$ in rat liver in vitro, an enzymatic process that we have termed $T_{3}$-neogenesis, is subject to the influence of the above-mentioned factors known or believed to affect $T_{3}$ formation from $\mathrm{T}_{4}$ in humans (33). Accordingly, we have proposed that $\mathrm{T}_{3}$-neogenesis in rat liver can serve as a suitable model of this process in man. Our earlier studies revealed that $T_{3}$ formation is impaired in preparations of liver from rats fasted for $2 \mathrm{~d}$, and that this effect can be prevented by the administration of glucose. This suggested that $T_{3}$-neogenesis is closely linked to glucose utilization, at least in this tissue (33). The present studies were designed to extend previous observations with this model, to further clarify the mechanism of impaired generation of $T_{3}$ from $T_{4}$ in liver from the fasted rat, and thereby to obtain insight into the factors that regulate this process in normal liver. Portions of this work have been presented in abstract form $(34,35)$.

\section{METHODS}

Hormones and chemicals. Isotopically labeled and stable iodothyronines, as well as the various cofactors and chemical agents employed in these studies, were obtained from commercial sources. ${ }^{2}$

Animals and dietary regimens. Male Sprague-Dawley rats weighing $150-200 \mathrm{~g}$ were purchased from Charles River Breeding Laboratories, Inc. (Wilmington, Mass.) and were routinely given a standard diet consisting of pelleted laboratory chow $^{3}$ and tap water ad libitum before the study (fed rats). During the final 48-h period, groups of rats were either maintained on the standard diet or deprived of chow but provided free access to drinking water (fasted rats). In other studies, some animals were given the standard diet, whereas others had chow withdrawn but were given free access to a solution of $25 \%$ glucose in place of the drinking water (glucose-replaced rats). In experiments involving fasting, all animals were given $\mathrm{T}_{4}, 1.5 \mu \mathrm{g} / 100 \mathrm{~g}$ body weight s.c. daily, as hypothyroidism is known to decrease

${ }^{2}$ Phenolic-ring ${ }^{125} I-$-labeled L-thyroxine (125 $\left.\mathrm{I}_{-1} \mathrm{~T}_{4}\right), \quad 50-70$ $\mu \mathrm{Ci} / \mu \mathrm{g}$ sp act, and $3,5,3^{\prime}$-L-triiodothyronine $\left({ }^{125} \mathrm{I}-\mathrm{T}_{3}\right), 50-75$ $\mu \mathrm{Ci} / \mu \mathrm{g}$, were purchased from Abbott Laboratories (Chicago, Ill.). Crystalline $\mathrm{T}_{4}$ and $\mathrm{T}_{3}, \mathrm{NAD}$ and NADH, NADP, NADPH, isocitric acid, isocitric acid dehydrogenase, GSH, GSSG, and diamide (azodicarboxylic acid-bis-dimethylamide) were all purchased from Sigma Chemical Co. (St. Louis, Mo.).

${ }^{3}$ Pelleted Laboratory Chow, RMH 1000, was purchased from Agway-Country Foods (Syracuse, N. Y.).
$\mathrm{T}_{3}$-neogenesis in rat liver $(36,37)$, and, in the rat, thyroid hypofunction is a consequence of fasting $(33,38)$.

Preparation and incubation of microsomes and cytosols from rat liver and kidney. Rats were killed by cervical subluxation, and livers and kidney were rapidly excised and weighed. A portion of liver or the entire kidney was homogenized (2:5, wt:vol) in a sucrose $(0.25 \mathrm{M})$-phosphate buffer $(0.06 \mathrm{M}), \mathrm{pH}$ 7.4. The homogenate was centrifuged at $10,000 \mathrm{~g}$ for $15 \mathrm{~min}$ at $4^{\circ} \mathrm{C}$, and the pellet was discarded. The supernate was centrifuged at $105,000 \mathrm{~g}$ for $\mathrm{l} \mathrm{h}$ and the resulting supernate (cytosol) was separated from the sedimented crude microsomal fraction by aspiration. The microsomal pellet was washed twice in $20 \mathrm{ml}$ of buffer by gentle homogenization, followed by resedimentation at $20,000 \mathrm{~g}$. The washed crude microsomal pellet was then dispersed in sucrose-phosphate buffer.

Aliquots of microsomal suspensions (200 $\mu \mathrm{l}$, equivalent to $300 \mathrm{mg}$ of liver or kidney) were added to $1.6 \mathrm{ml}$ of phosphatesucrose buffer, or the same volume of liver or kidney cytosol, previously enriched with ${ }^{125} \mathrm{I}_{-} \mathrm{T}_{4}(1 \mu \mathrm{Ci} / \mathrm{ml}, 0.020 \mu \mathrm{g} / \mathrm{ml})$ or ${ }^{125} \mathrm{I}_{-} \mathrm{T}_{3}(1.3 \mu \mathrm{Ci} / \mathrm{ml}, 0.025 \mu \mathrm{g} / \mathrm{ml})$. Cofactors or chemicals dissolved in $300 \mu \mathrm{l}$ of buffer or the same volume of buffer alone were then added to attain a final incubation volume of $2.1 \mathrm{ml}$. The resulting mixtures were incubated for $3 \mathrm{~h}$ at $37^{\circ} \mathrm{C}$ under an atmosphere of $\mathrm{N}_{2}$. Under these conditions, the generation of ${ }^{125} \mathrm{I}-\mathrm{T}_{3}$ from ${ }^{125} \mathrm{I}-\mathrm{T}_{4}$ in mixtures of microsomes in either buffer or cytosol increased progressively over a 4-h incubation period. In all experiments, two types of control vessels were employed, one containing tissue fractions and labeled hormone, but incubated at $0^{\circ} \mathrm{C}$, and the other incubated at $37^{\circ} \mathrm{C}$, but containing no tissue. Where appropriate, control vessels contained the same chemical or cofactor additives that were present in experimental vessels. No significant degradation of ${ }^{125} \mathrm{I}_{-} \mathrm{T}_{4}$ or generation of ${ }^{125} \mathrm{I}-\mathrm{T}_{3}$ was observed in these control preparations. After incubation, vessels were quickly placed on cracked ice, and portions of the complete reaction mixtures were combined with equal volumes of blood bank plasma and stored frozen at $-20^{\circ} \mathrm{C}$ for subsequent analysis by paper chromatography.

Paper chromatography. Frozen reaction mixtures were thawed and mixed thoroughly, and $10-\mu l$ aliquots were applied together with carrier compounds to Whatman $3 \mathrm{MM}$ (Whatman, Inc., Clifton, N. J.) paper chromatographic strips. The strips were chromatographed in a descending hexane-tertiary amyl alcohol-2 $\mathrm{N}$ ammonia (1:10:11) solvent system. Chromatograms were dried; carrier iodothyronines were localized with the aid of ultraviolet light and carrier iodide $\left(\mathrm{I}^{-}\right)$by spraying with palladium chloride. Zones corresponding to the origin and carrier compounds were excised and counted in a gamma scintillation counter. Over $98 \%$ of the total radioactivity recovered from chromatograms between the origin and the solvent front was contained in these discrete zones. Values for the percentage generation of labeled products during incubations with ${ }^{125} \mathrm{I}-\mathrm{T}_{4}$ or ${ }^{125} \mathrm{I}_{-} \mathrm{T}_{3}$ were corrected for the percentage contamination of these products found in nonmetabolizing control vessels. ${ }^{125} \mathrm{I}_{-} \mathrm{T}_{4}$ was 96-97\% pure, containing $0.3-0.5 \%{ }^{125} \mathrm{I}_{-} \mathrm{T}_{3}$ and $1-2 \%{ }^{125} \mathrm{I}_{-} \mathrm{I}^{-}$as contaminants, whereas ${ }^{125} \mathrm{I}-\mathrm{T}_{3}$ was $95 \%$ pure and contained $2 \%{ }^{125} \mathrm{I}_{-} \mathrm{I}^{-}$as the only definable contaminant.

Protein measurements. The method of Lowry and co-workers (39) was employed to measure protein concentrations in preparations of either cytosol or microsomes that had been dispersed in $0.1 \%$ deoxycholate.

Statistical analysis. All experiments were performed three or more times, with close concurrence of the results obtained. Hence, results were pooled and subjected to statistical analysis by the Student's $t$ test when a single experimental variable was studied. When more than two 
variables were studied, the significance of differences between results in specific groups was assessed by analysis of variance, followed by Duncan's multiple range test (40).

\section{RESULTS}

In all of the studies performed, only ${ }^{125}$ I-labeled $T_{3}$, $\mathrm{I}^{-}$, origin material $(\mathrm{OM})$, and a compound with the chromatographic mobility of 3,5,3',5'-tetraiodothyroacetic acid, appeared as products of ${ }^{125} \mathrm{I}_{-} \mathrm{T}_{4}$ metabolism. Labeled reverse $T_{3}$ was not detected, presumably because of its rapid degradation. The principle focus of these investigations was the formation of $T_{3}$ from $\mathrm{T}_{4}$; hence, only results concerning the quantity of $\mathrm{T}_{4}$ degraded and the quantities of $\mathrm{T}_{3}$ and $\mathrm{I}^{-}$formed will be discussed. ${ }^{125}$ I-Labeled origin material and carrier $3,5,3^{\prime}, 5^{\prime}$-tetraiodothyroacetic acid never accounted for more than a few percent of total ${ }^{125}$ I on final chromatograms, and results with respect to these compounds will not be presented or discussed. ${ }^{4}$

${ }^{4}$ An Appendix containing a complete tabulation of all the results of the experiments presented in this manuscript, together with statistical analyses of the significance of differences between means for all functions measured among all experimental groups, has been deposited with the National
$T_{3}$ generation from $T_{4}$ by microsomes incubated in buffer. In a series of 18 experiments, the proportion of ${ }^{125} \mathrm{I}-\mathrm{T}_{3}$ present after incubation of microsomes in buffer was compared with that found after incubation of tissue-free controls. Values averaged $1.4 \pm 0.6 \%$ (mean $\pm \mathrm{SE}$ ) of added $\mathrm{T}_{4}$ in the presence of microsomes and $0.6 \pm 0.1 \%$ in the absence of microsomes $(P<0.001)$. This indicates that very slight, but significant, generation of $\mathrm{T}_{3}$ takes place in microsomes incubated in buffer alone.

Effects of fasting. When incubated in buffer, liver microsomes from fed and from fasted rats generated similar quantities of ${ }^{125} \mathrm{I}_{-} \mathrm{T}_{3}$ from ${ }^{125} \mathrm{I}-\mathrm{T}_{4}$. When liver cytosol from fed rats was substituted for buffer, generation of ${ }^{125} \mathrm{I}_{-} \mathrm{T}_{3}$ was increased approximately threefold, regardless of whether microsomes had been obtained from fed or fasted rats (Table I). Moreover, when liver cytosol from fed rats was replaced by

Auxiliary Publications Service (NAPS) document 03436. This information may be ordered from ASIS/NAPS, Microfiche Publications, P.O. Box 3513 Grand Central Station, New York 10017. Remit in advance $\$ 3.00$ for microfiche copy, or for photocopy, $\$ 5.00$ up to 20 pages plus $25 t$ for additional pages. Checks should be made payable to Microfiche Publications.

TABLE I

Effect of Fasting on the Metabolism of ${ }^{125}{ }^{1-} T_{4}$ in Mixtures of Microsomes and Buffer and Microsomes and Cytosols from Rat Liver

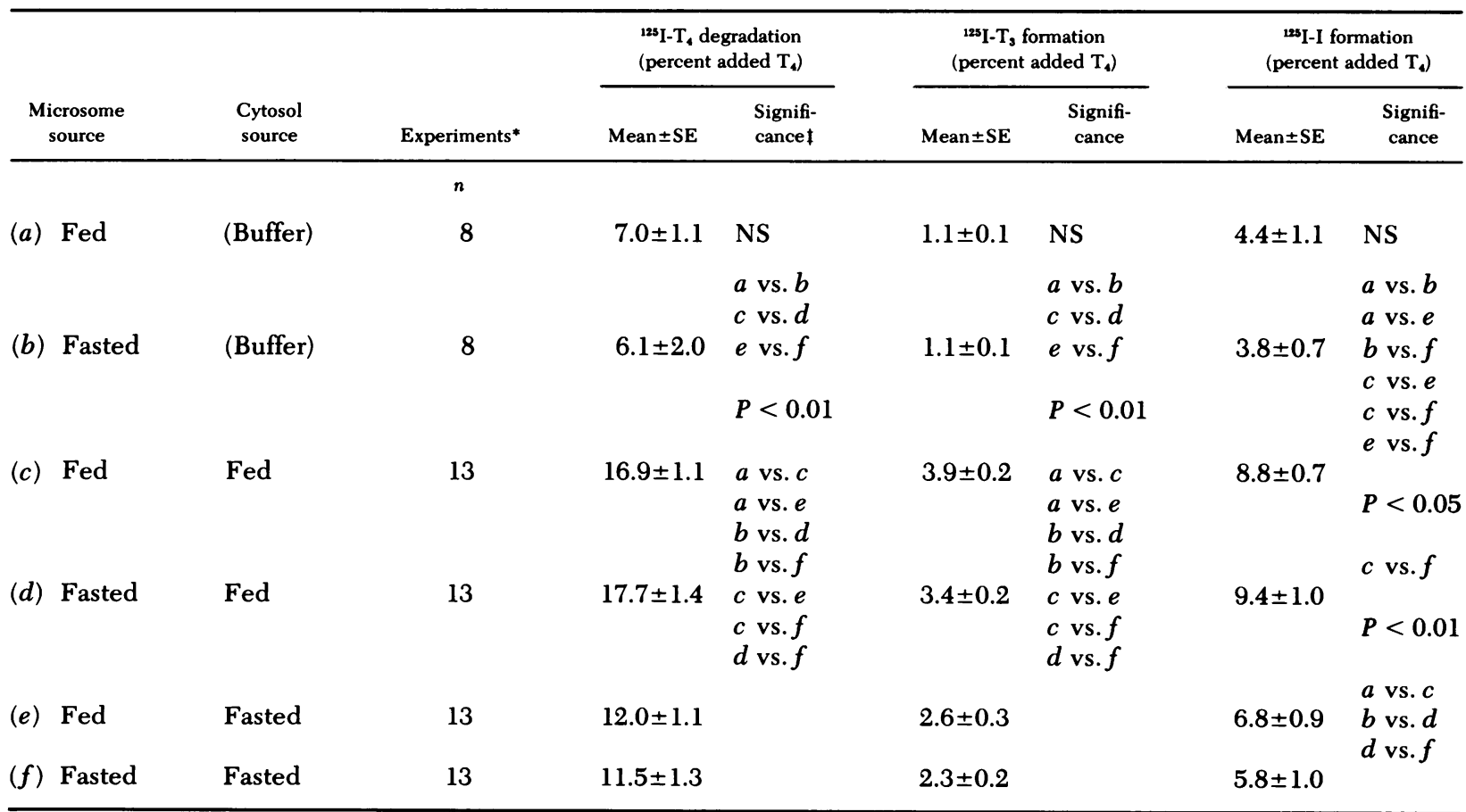

* Number of separate experiments performed for each experimental group.

‡ Levels of statistical significance of differences between values among various experimental groups. Analyses shown only for those comparisons considered to be important. 
cytosol from fasted rats, generation of ${ }^{125} \mathrm{I}-\mathrm{T}_{3}$ was greatly decreased, and again values obtained with microsomes from fed and fasted animals did not differ significantly. However, even cytosol from fasted rats provided significantly greater support of $T_{3}$-neogenesis than buffer alone did. As with $T_{3}$ formation, the degradation of $\mathrm{T}_{4}$ and formation of $\mathrm{I}^{-}$were least in incubations containing buffer, greater in those containing cytosol from fasted rats, and greatest in those containing cytosol from fed rats.

As judged from six experiments, livers from fed and fasted animals did not differ significantly in the protein concentrations (milligrams per gram wet liver weight) of their respective microsomes $(11.6 \pm 0.6$ vs. $10.5 \pm 1.1)$ or cytosols $(56.7 \pm 3.8$ vs. $62.7 \pm 2.9)$.

Effects of glucose replacement. Comparable experiments were performed with varying mixtures of microsomes and cytosols derived from fed or glucose-replaced rats because previous studies had shown that glucose administration prevented the decreased $T_{3}$-neogenesis otherwise found in homogenates and slices of liver from fasted animals. In these experiments, $T_{3}$ formation was again greater in the presence of cytosol than of buffer and, with respect to either microsomal activity or cytosolic stimulation, there was no difference between preparations from chow-fed and glucosereplaced animals (data not shown).

Effects of fasting in varying mixtures of microsomes and cytosols from liver and kidney. In earlier studies, we have demonstrated that after a 48-h period of fasting, $T_{3}$ formation is diminished in preparations from liver, but not from kidney. This observation served as the rationale for assessing the effect of fasting on $\mathrm{T}_{3}$ generation in varying mixtures of liver and kidney microsomes and cytosols from fed and fasted animals (Table II). In the presence of liver cytosol from fed rats, kidney microsomes from fed and fasted rats did not differ in $\mathrm{T}_{3}$-neogenetic activity. The same was true when kidney microsomes were incubated in liver cytosol from fasted animals, though the level of activity was significantly less.

Converse experiments were performed in which liver microsomes from fed or fasted animals were incubated with kidney cytosol from the same two sources. $\mathrm{T}_{3}$-neogenesis in the four different combinations was essentially the same. This was also true when

TABLE II

Effect of Fasting on the Metabolism of ${ }^{125}{ }^{12} T_{4}$ in Mixtures of Microsomes and Cytosols from Livers and Kidneys of Rats

\begin{tabular}{|c|c|c|c|c|c|c|c|c|}
\hline \multirow[b]{2}{*}{$\begin{array}{l}\text { Microsome } \\
\text { source }\end{array}$} & \multirow[b]{2}{*}{$\begin{array}{l}\text { Cytosol } \\
\text { source }\end{array}$} & \multirow[b]{2}{*}{ Experiments* } & \multicolumn{2}{|c|}{$\begin{array}{l}{ }^{125} \mathrm{I}-\mathrm{T}_{4} \text { degradation } \\
\text { (percent added } \mathrm{T}_{4} \text { ) }\end{array}$} & \multicolumn{2}{|c|}{$\begin{array}{c}{ }^{125} \mathrm{I}-\mathrm{T}_{3} \text { formation } \\
\text { (percent added } T_{4} \text { ) }\end{array}$} & \multicolumn{2}{|c|}{$\begin{array}{c}{ }^{125} \mathrm{I}-\mathrm{I} \text { formation } \\
\text { (percent added } \mathrm{T}_{4} \text { ) }\end{array}$} \\
\hline & & & Mean \pm SE & $\begin{array}{l}\text { Signifi- } \\
\text { cancet }\end{array}$ & Mean $\pm S E$ & $\begin{array}{l}\text { Signifi- } \\
\text { cance }\end{array}$ & Mean \pm SE & $\begin{array}{c}\text { Signifi- } \\
\text { cance }\end{array}$ \\
\hline
\end{tabular}

Kidney microsomes and liver cytosols

(a) Fed, kidney

(b) Fasted, kidney

Fed, liver

Fed, liver

(c) Fed, kidney

Fasted, liver

Fasted, liver

(d) Fasted, kidney $n$

7

7

7

7

$9.5 \pm 1.8$

$\begin{array}{cc}12.5 \pm 2.5 & \text { NS } \\ 9.5 \pm 1.1 & a \text { vs. } b \\ & a \text { vs. } c \\ 10.6 \pm 1.9 & b \text { vs. } d \\ & c \text { vs. } d \\ 9.5 \pm 1.8 & \end{array}$

Liver microsomes and kidney cytosols

$$
\text { Fed, kidney }
$$

(b) Fasted, liver

Fed, kidney

(c) Fed, liver

Fasted, kidney

Fasted, kidney

(d) Fasted, liver
9

9

8

8

$\begin{array}{cc}14.1 \pm 1.9 & \text { NS } \\ 17.3 \pm 1.5 & a \text { vs. } b \\ & a \text { vs. } c \\ 15.6 \pm 2.8 & b \text { vs. } d \\ & c \text { vs. } d\end{array}$

$17.7 \pm 1.9$

\begin{tabular}{cl}
$2.2 \pm 0.1$ & \multicolumn{1}{c}{ NS } \\
$2.3 \pm 0.4$ & $\begin{array}{l}a \text { vs. } b \\
c \text { vs. } d\end{array}$ \\
$1.3 \pm 0.2$ & $\begin{array}{l}P<0.05 \\
a \text { vs. } c\end{array}$ \\
$0.8 \pm 0.2$ & $\begin{array}{l}P<0.01 \\
b \text { vs. } d\end{array}$ \\
& \\
$2.4 \pm 0.3$ & NS \\
$2.2 \pm 0.2$ & $\begin{array}{l}a \text { vs. } b \\
a \text { vs. } c\end{array}$ \\
$1.8 \pm 0.3$ & $\begin{array}{l}b \text { vs. } d \\
c \text { vs. } d\end{array}$ \\
$1.9 \pm 0.2$ &
\end{tabular}

$5.1 \pm 1.4$

NS

$2.8 \pm 0.9$

$a$ vs. $b$

$a$ vs. $c$

$4.3 \pm 0.8$

$b$ vs. $d$

$c$ vs. $d$

$4.1 \pm 1.1$

$4.1 \pm 1.1$

* Number of separate experiments performed for each experimental group.

† Levels of statistical significance of differences between values among various experimental groups. Analyses shown only for those comparisons considered to be important. 
kidney microsomes from fed or fasted rats were mixed with kidney cytosol from the same two sources (data not shown).

Effect of NADPH. Experiments were conducted to assess the effect of adding an NADPH-generating system to liver microsomes from fed or fasted rats incubated either in buffer or in liver cytosols from fed or fasted animals (Table III). ${ }^{5}$ In the presence of buffer, $\mathrm{T}_{3}$-neogenesis by microsomes was not enhanced significantly by NADPH. Neither did NADPH further increase the stimulatory effect of cytosol from animals that had been fed. However, NADPH enrichment of cytosol from fasted animals restored microsomal $\mathrm{T}_{3}$-neogenesis to the greater activity seen in the

${ }^{5}$ Although the experiments shown in Table III involved studies of microsomes from fasted as well as fed animals, only results obtained in microsomes from fed animals are shown, as no difference in the responsiveness of microsomes from fed or fasted animals was seen in these or any of the other experiments described. presence of cytosol from fed animals. In none of the foregoing mixtures did NADH significantly influence $\mathrm{T}_{3}$-neogenesis (data not shown). In mixtures of microsomes with cytosol from fed animals, NADPH consistently appeared to decrease both ${ }^{125} \mathrm{I}_{-} \mathrm{T}_{4}$ degradation and ${ }^{125} \mathrm{I}-\mathrm{I}^{-}$formation, though the differences were not statistically significant by the methods of analysis employed.

Effect of GSH. Previous studies have shown that various mercaptans stimulate the $T_{3}$-neogenesis in liver homogenates (41) and microsomes (42-44). Therefore, experiments were performed to assess the effect of GSH in microsomes incubated in buffer or in cytosols obtained from either fed or fasted rats (Table IV). In these and ensuing studies, all microsomes were derived from the livers of fed rats.

Liver cytosol from fed animals was again found to be more supportive of $\mathrm{T}_{3}$-neogenesis than was cytosol from fasted animals. In the presence of cytosol from fed animals, addition of $\mathrm{GSH}(5 \mathrm{mM})$ increased $\mathrm{T}_{3}$ formation slightly, but significantly. Similar enrichment of

\section{TABLE III}

Effect of NADPH on the Metabolism of ${ }^{125} I_{-} T_{4}$ in Mixtures of Liver Microsomes from Fed Rats with Buffer or Liver Cytosols from Fed and Fasted Rats

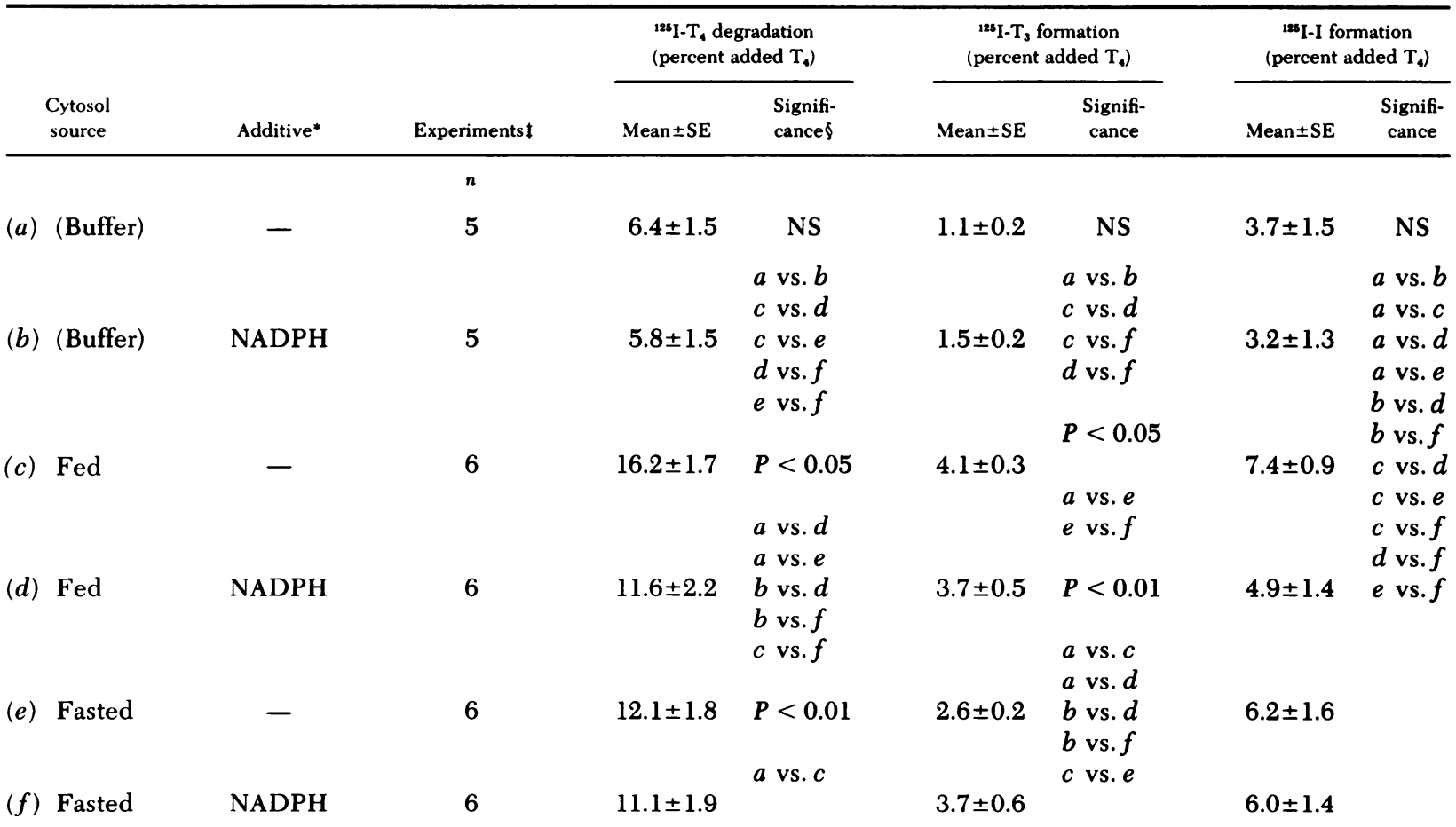

* NADPH added as an NADPH-generating system: isocitric acid dehydrogenase, $1 \mathrm{mg} / \mathrm{ml}$, isocitric acid, $20 \mathrm{mM}$, and NADP, $0.1 \mathrm{mM}$.

\$ Number of separate experiments performed for each experimental group.

$\S$ Levels of statistical significance of differences between values among various experimental groups. Analyses shown only for those comparisons considered to be important. 
TABLE IV

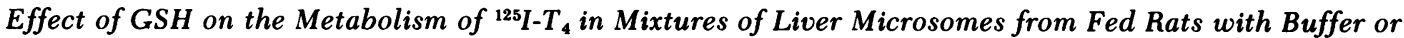
Liver Cytosols from Fed and Fasted Rats

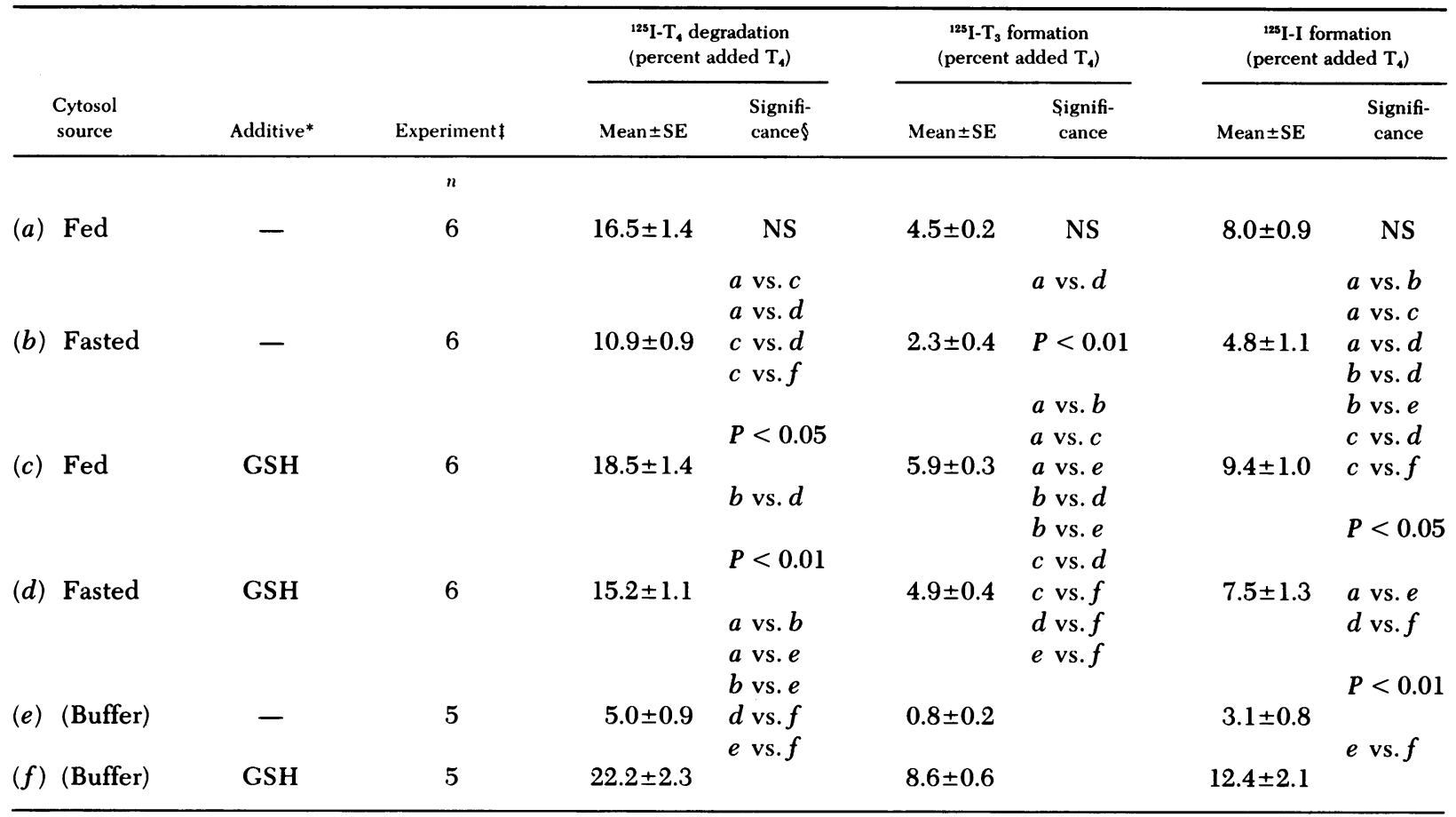

* GSH, $5 \mathrm{mM}$.

$\$$ Number of separate experiments performed for each experimental group.

$\S$ Levels of statistical significance of differences between values among various experimental groups. Analyses shown only for those comparisons considered to be important.

preparations containing cytosol from fasted animals increased $\mathrm{T}_{3}$ formation more markedly, and values were then comparable to those seen in mixtures containing cytosol from fed animals. $\mathrm{T}_{4}$ degradation was increased significantly by GSH in mixtures containing cytosol from fasted animals, but not from fed animals.

In preparations containing microsomes in buffer, GSH increased $\mathrm{T}_{3}$ generation $>10$-fold, and both the disappearance of $T_{4}$ and generation of iodide were also markedly enhanced. This finding was in marked contrast to that obtained with NADPH, which had no effect on microsomal $T_{3}$-neogenesis in the absence of cytosol.

The effects of GSSG $(5 \mathrm{mM})$ in these systems were quite distinct from those of GSH. Thus, in four experiments, values for percentage microsomal generation of $\mathrm{T}_{3}$ in the presence of cytosol from fed animals were: (a) $3.1 \pm 0.4$ in the absence of any additions; (b) $4.3 \pm 0.4$ in the presence of $\mathrm{GSH}$; and (c) $2.0 \pm 0.2$ in the presence of GSSG ( $a$ vs. $b, P<0.05 ; b$ vs. $c, P<0.01$; $a$ vs. $c$, NS). Corresponding values obtained when microsomes were incubated in buffer, rather than cytosol, were: $(a) 0.5 \pm 0.1 ;(b) 7.9 \pm 0.3$; and $(c) 0.4 \pm 0.1$ ( $a$ vs. $b, P<0.01 ; b$ vs. $c, P<0.01 ; a$ vs. $c, N S$ ).

Effect of diamide. To determine the relationship between the actions of NADPH and GSH within these systems, experiments were performed to ascertain the effects of the sulfhydryl oxidant, diamide (45), in microsomal preparations suspended in either cytosol or buffer (Table V). As previously seen, $T_{3}$ formation in the presence of cytosol from fasted rats was enhanced by the addition of GSH. In this system, diamide greatly decreased $\mathrm{T}_{3}$ formation and blocked the stimulatory effect of added GSH. In the presence of buffer, rather than cytosol, values for microsomal $\mathrm{T}_{3}$ generation were low and were unaffected by diamide. GSH was once again seen to stimulate enzyme activity $>10$-fold and, as expected, diamide prevented this effect. Effects of GSH and diamide, separately and in combination, on $\mathrm{T}_{4}$ degradation and $\mathrm{I}^{-}$formation were parallel to their effects on $\mathrm{T}_{3}$-neogenesis. 
TABLE V

Effect of Diamide and Cofactors on the Metabolism of ${ }^{125} I_{-} T_{4}$ in Mixtures of Liver Microsomes from Fed Rats with Buffer or Cytosols from Livers of Fed and Fasted Rats

\begin{tabular}{|c|c|c|c|c|c|c|c|c|}
\hline \multirow[b]{2}{*}{$\begin{array}{l}\text { Cytosol } \\
\text { source }\end{array}$} & \multirow[b]{2}{*}{ Additive* } & \multirow[b]{2}{*}{ Experiment! } & \multicolumn{2}{|c|}{$\begin{array}{l}{ }^{125} \mathrm{I}-\mathrm{T}_{4} \text { degradation } \\
\text { (percent added } T_{4} \text { ) }\end{array}$} & \multicolumn{2}{|c|}{$\begin{array}{l}{ }^{125} \mathrm{I}_{-} \mathrm{T}_{3} \text { formation } \\
\text { (percent added } T_{4} \text { ) }\end{array}$} & \multicolumn{2}{|c|}{$\begin{array}{c}{ }^{125} \mathrm{I} \text {-I formation } \\
\left.\text { (percent added } \mathrm{T}_{4}\right)\end{array}$} \\
\hline & & & Mean \pm SE & $\begin{array}{l}\text { Signifi- } \\
\text { cance }\end{array}$ & Mean $\pm S E$ & $\begin{array}{l}\text { Signifi- } \\
\text { cance }\end{array}$ & Mean $\pm S E$ & $\begin{array}{c}\text { Signifi- } \\
\text { cance }\end{array}$ \\
\hline
\end{tabular}

Effect of diamide and GSH

\begin{tabular}{|c|c|c|c|c|c|c|c|c|c|}
\hline (a) & Fasted & - & 6 & $8.1 \pm 1.7$ & NS & $1.6 \pm 0.4$ & NS & $3.9 \pm 1.2$ & NS \\
\hline (b) & Fasted & GSH & 6 & $12.3 \pm 1.0$ & $\begin{array}{l}a \text { vs. } c \\
c \text { vs. } d\end{array}$ & $3.9 \pm 0.3$ & $\begin{array}{l}c \text { vs. } d \\
c \text { vs. } e\end{array}$ & $6.5 \pm 0.7$ & $\begin{array}{l}c \text { vs. } d \\
c \text { vs. } e\end{array}$ \\
\hline (c) & Fasted & Diamide & 6 & $5.0 \pm 0.5$ & $\begin{array}{l}c \text { vs. } e \\
e \text { vs. } f\end{array}$ & $0.4 \pm 0.3$ & $\begin{array}{l}e \text { vs. } f \\
e \text { vs. } h\end{array}$ & $1.2 \pm 0.3$ & $\begin{array}{l}e \text { vs. } f \\
e \text { vs. } h\end{array}$ \\
\hline (d) & Fasted & GSH and diamide & 6 & $4.6 \pm 0.7$ & $\begin{array}{l}e \text { vs. } h \\
f \text { vs. } h\end{array}$ & $0.3 \pm 0.1$ & $f$ vs. $h$ & $1.9 \pm 0.4$ & $f$ vs. $h$ \\
\hline$(e)$ & (Buffer) & - & 5 & $5.1 \pm 1.1$ & $P<0.05$ & $0.4 \pm 0.1$ & $P<0.01$ & $3.6 \pm 0.9$ & $P<0.05$ \\
\hline$(f)$ & (Buffer) & Diamide & 5 & $6.2 \pm 0.9$ & $a$ vs. $b$ & $0.5 \pm 0.1$ & $\begin{array}{l}a \text { vs. } b \\
a \text { vs. } c\end{array}$ & $3.5 \pm 0.6$ & $\begin{array}{l}a \text { vs. } b \\
a \text { vs. } c\end{array}$ \\
\hline (g) & (Buffer) & GSH & 5 & $19.4 \pm 1.4$ & & $6.5 \pm 0.6$ & $\begin{array}{l}b \text { vs. } d \\
e \text { vs. } g\end{array}$ & $9.5 \pm 1.5$ & $b$ vs. $d$ \\
\hline (h) & (Buffer) & GSH and diamide & 5 & $8.3 \pm 1.2$ & $\begin{array}{l}b \text { vs. } d \\
e \text { vs. } g \\
g \text { vs. } h\end{array}$ & $0.7 \pm 0.1$ & g vs. $h$ & $5.7 \pm 0.8$ & $\begin{array}{l}P<0.01 \\
e \text { vs. } g \\
g \text { vs. } h\end{array}$ \\
\hline
\end{tabular}

Effect of diamide and NADPH

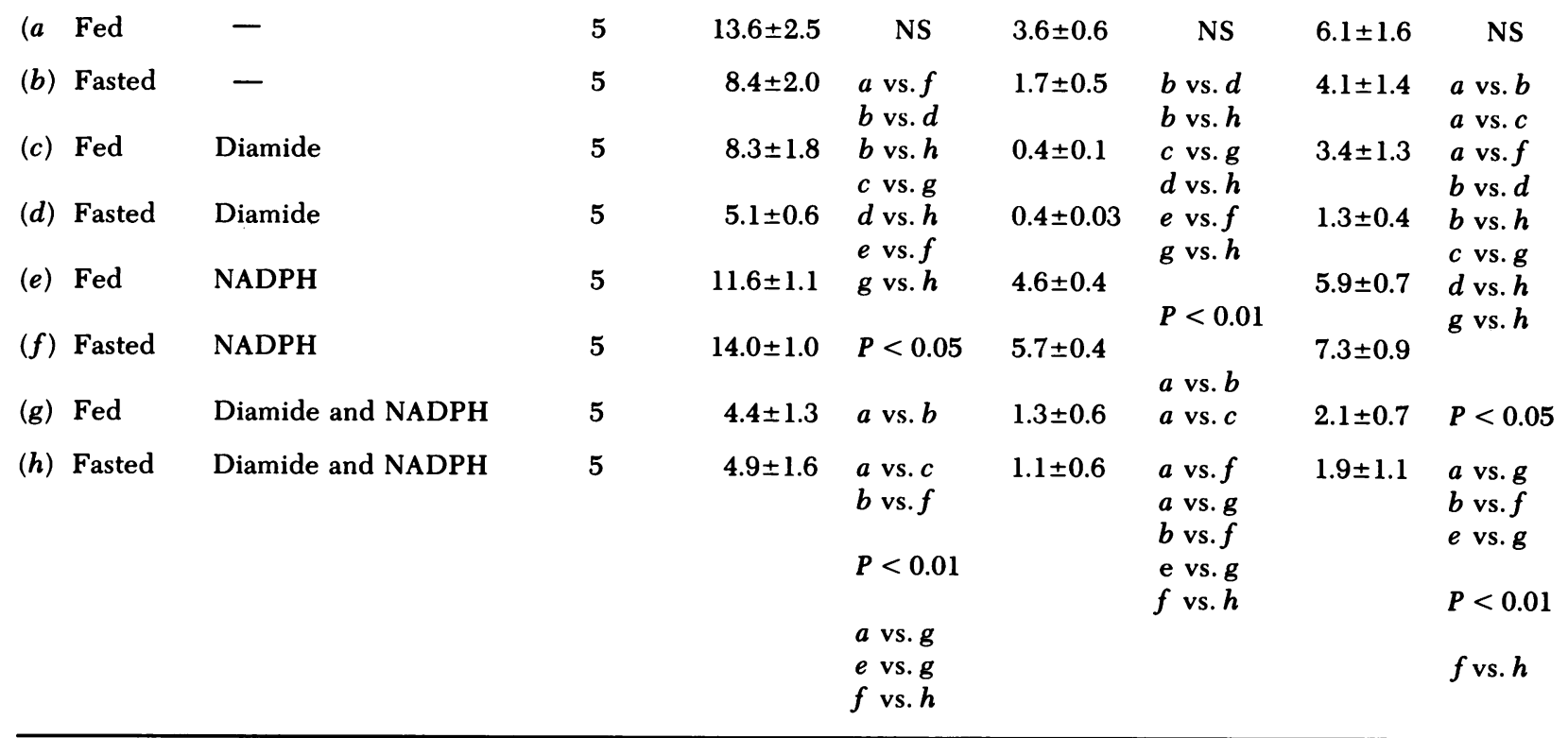

* GSH, $5 \mathrm{mM}$, diamide, $10 \mathrm{mM}$, and NADPH as a NADPH-generating system: isocritic acid dehydrogenase, $1 \mathrm{mg} / \mathrm{ml}$, isocritic acid, $20 \mathrm{mM}$, and NADP, $0.1 \mathrm{mM}$.

$\$$ Number of separate experiments performed for each experimental group.

$\S$ Levels of statistical significance of differences between values among various experimental groups. Analyses shown only for those comparisons considered to be important. 
As observed in previous experiments, NADPH had no significant effect on microsomal $T_{3}$-neogenesis in the presence of cytosol from fed animals, but restored values in the presence of fasted cytosol to those seen in the former group. With both types of cytosol, with or without NADPH, $\mathrm{T}_{3}$-neogenesis was substantially inhibited by diamide. In all combinations tested, diamide diminished, but did not abolish, $\mathrm{T}_{4}$ degradation and the generation of $\mathrm{I}^{-}$.

Effect of cofactors on the metabolism of ${ }^{125} I-T_{3}$. Relative to rates of ${ }^{125} \mathrm{I}-\mathrm{T}_{4}$ degradation and ${ }^{125} \mathrm{I}$ generation therefrom, rates of ${ }^{125} \mathrm{I}_{-} \mathrm{T}_{3}$ degradation under comparable conditions were quite low. In microsomal preparations incubated with cytosol from fed animals, NADPH decreased both $\mathrm{T}_{3}$ degradation and $\mathrm{I}^{-}$generation, whereas GSH had little effect (Table VI). $\mathrm{T}_{3}$ metabolism was slower in mixtures containing cytosol from fasted than from fed rats, and no significant changes were detected after the addition of cofactors to cytosol from fasted animals. The effects of NADPH and possibly GSH on $T_{3}$ metabolism by microsomes incubated in buffer differed from their effects on $T_{3}$-neogenesis under these conditions. Thus, NADPH had an inhibitory effect on $\mathrm{T}_{3}$ degradation, though it had not affected $T_{3}$ formation under these conditions. Moreover, although GSH enhanced $T_{3}$ degradation, as it had in the case of $T_{4}$, the proportionate effect was far less in the case of $T_{3}$.

\section{DISCUSSION}

In a previous report (33), we presented evidence that $\mathrm{T}_{3}$-neogenesis in slices or homogenates of rat liver provides a reliable model of this process in man. Among

TABLE VI

Effects of Cofactors on the Metabolism of ${ }^{125}{ }^{2} T_{3}$ in Mixtures of Liver Microsomes from Fed Rats with Buffer or Liver Cytosols from Fed and Fasted Rats

\begin{tabular}{|c|c|c|c|c|c|c|c|}
\hline \multirow{2}{*}{\multicolumn{2}{|c|}{$\begin{array}{l}\text { Cytosol } \\
\text { source }\end{array}$}} & \multirow[b]{2}{*}{ Additive* } & \multirow[b]{2}{*}{ Experiments } & \multicolumn{2}{|c|}{$\begin{array}{l}{ }^{125} \mathrm{I}-\mathrm{T}_{3} \text { degradation } \\
\text { (percent added } \mathrm{T}_{3} \text { ) }\end{array}$} & \multicolumn{2}{|c|}{$\begin{array}{l}\text { 125I-I formation } \\
\text { (percent added } \mathrm{T}_{3} \text { ) }\end{array}$} \\
\hline & & & & Mean $\pm \mathrm{SE}$ & $\begin{array}{l}\text { Signifi- } \\
\text { cance }\end{array}$ & Mean \pm SE & $\begin{array}{l}\text { Signifi- } \\
\text { cance }\end{array}$ \\
\hline & & & $n$ & & & & \\
\hline (a) & Fed & - & 8 & $6.7 \pm 1.6$ & NS & $3.5 \pm 1.0$ & NS \\
\hline (b) & Fed & NADPH & 8 & $1.7 \pm 0.2$ & $\begin{array}{l}a \text { vs. } c \\
a \text { vs. } f \\
b \text { vs. } e\end{array}$ & $1.7 \pm 0.2$ & $\begin{array}{l}a \text { vs. } d \\
a \text { vs. } e \\
a \text { vs. } f\end{array}$ \\
\hline$(c)$ & Fed & GSH & 5 & $8.6 \pm 1.9$ & $\begin{array}{l}d \text { vs. } e \\
d \text { vs. } f \\
e \text { vs. } f\end{array}$ & $5.9 \pm 1.4$ & $\begin{array}{l}b \text { vs. } e \\
d \text { vs. } e \\
d \text { vs. } f\end{array}$ \\
\hline (d) & Fasted & - & 6 & $3.3 \pm 0.8$ & $P<0.05$ & $1.6 \pm 0.4$ & $P<0.05$ \\
\hline$(e)$ & Fasted & NADPH & 6 & $2.1 \pm 0.4$ & $\begin{array}{l}a \text { vs. } d \\
c \text { vs. } f\end{array}$ & $1.5 \pm 0.3$ & $\begin{array}{l}a \text { vs. } b \\
a \text { vs. } c\end{array}$ \\
\hline$(f)$ & Fasted & GSH & 4 & $4.5 \pm 1.2$ & $\begin{array}{l}P<0.01 \\
a \text { vs. } b\end{array}$ & $2.3 \pm 0.8$ & $\begin{array}{l}a \text { vs. } g \\
g \text { vs. } h\end{array}$ \\
\hline (g) & (Buffer) & - & 8 & $2.6 \pm 0.4$ & $\begin{array}{l}a \text { vs. } e \\
a \text { vs. } g \\
g \text { vs. } h\end{array}$ & $1.8 \pm 0.3$ & $\begin{array}{l}P<0.01 \\
c \text { vs. } f\end{array}$ \\
\hline (h) & (Buffer) & NADPH & 8 & $0.9 \pm 0.2$ & $\begin{array}{l}g \text { vs. } i \\
h \text { vs. } i\end{array}$ & $0.9 \pm 0.2$ & $\begin{array}{l}g \text { vs. } i \\
h \text { vs. } i\end{array}$ \\
\hline (i) & (Buffer) & GSH & 6 & $4.1 \pm 0.4$ & & $3.7 \pm 0.5$ & \\
\hline
\end{tabular}

* GSH, $5 \mathrm{mM}$, NADPH added as an NADPH-generating system: isocitric acid dehydrogenase, $1 \mathrm{mg} / \mathrm{ml}$ isocitric acid, $20 \mathrm{mM}$, and NADP, $0.1 \mathrm{mM}$.

† Number of separate experiments performed for each experimental group.

\$ Levels of statistical significance of differences between values among various experimental groups. Analyses shown only for those comparisons considered to be important. 
the evidence in support of this suggestion was the finding that a 48-h fast in the rat greatly reduced $T_{3}$-neogenesis from $T_{4}$ in liver preparations in vitro, and this finding seemed to correlate with the known reduction in overall $T_{3}$-neogenesis that occurs during periods of fasting in man.

In the present studies, we have sought to determine the factors responsible for the decrease in hepatic formation of $T_{3}$ from $T_{4}$ occasioned by fasting and to elucidate thereby certain of the factors that regulate the activity of the $5^{\prime}$-monodeiodinating mechanism for $T_{4}$. To do this, we have examined the $T_{3}$-neogenetic activity of particular hepatic subcellular fractions, alone and in combination, from normal and fasted animals, with and without added cofactors. Specifically, we have examined the activity of crude microsomal preparations, in which the 5 '-monodeiodinating enzyme is thought to reside $(42,43)$ and have studied the influence thereon of hepatic cytosol, a subcellular fraction virtually devoid of intrinsic deiodinase activity. Our observations are consonant with others that indicate that crude microsomal preparation is richest in $5^{\prime}$-monodeiodination for $T_{4}(42-44)$, because under any given condition this fraction was more active on a unit protein basis than nuclear, mitochondrial, or cytosolic fractions were (data not shown). Distinct, though low, activity was present in microsomes incubated in buffer, because values for $T_{3}$ generation, though small, consistently exceeded those found in tissue-free or unincubated controls. The data further provided clear evidence of the existence of stimulatory cofactors within the cytosol, because incubation of microsomes in cytosol invariably yielded greater proportions of $T_{3}$ than were found during incubations of microsomes in buffer alone.

Several lines of evidence indicated that the defective hepatic $T_{3}$-neogenesis associated with a 48 -h period of fasting was the result of a cytosolic, rather than a microsomal, abnormality. Microsomes from liver of fed and fasted rats displayed similar $\mathrm{T}_{3}$-neogenetic activity, which was lowest when incubated in buffer, greater when cytosol from fasted animals was employed, and greatest when cytosol from fed animals was the suspending vehicle.

Further evidence to this point was provided by experiments in which microsomes and cytosols from liver of fed or fasted animals were variously mixed with analogous fractions from kidney, previous studies in homogenates and slices having shown that renal $\mathrm{T}_{3}$-neogenesis in vitro is unaffected by a 48-h fast. When only renal microsomes and cytosols were used, $T_{3}$ formation from $T_{4}$ was essentially the same in all four combinations of microsomes and cytosols from fed and fasted animals (data not shown). This finding tends to validate the use of the recombination system as a reflection of $T_{3}$-neogenesis in unfractionated homogenates. Hence, the fact that $T_{3}$ formation was unaffected by the nutritional state of the donor of hepatic microsomes or of renal cytosol provided further indication of the normality of microsomal enzyme in the liver of the fasted rat. In contrast, cytosol from livers of fasted rats was consistently less supportive of $\mathrm{T}_{3}$-neogenesis by renal microsomes than was hepatic cytosol from fed rats.

From the foregoing observations we would conclude that in the rat fasted for $48 \mathrm{~h}$ the defect in hepatic $\mathrm{T}_{3}$-neogenesis resides in deficient cytosolic support, rather than an intrinsic abnormality in the $5^{\prime}$-monodeiodinating enzyme. From studies in livers of animals fasted for $72 \mathrm{~h}$, Kaplan (44) has concluded that fasting is associated with both cytosolic and microsomal abnormalities. We have confirmed that this is the case in animals fasted for this period, but our own data indicate that the microsomal abnormality is secondary to the hypothyroidism that supervenes in the fasted animal, because it is prevented by the administration of physiological replacement doses of $\mathrm{T}_{4}$ during the period of fasting. ${ }^{6}$ It was for this reason that all animals in the present studies, controls as well as those fasted, were given exogenous $\mathrm{T}_{4}$.

As anticipated from our previous observations in whole homogenates or slices, abnormalities in the hepatic cytosol were prevented by giving the donor rats $25 \%$ glucose in the drinking water during the period of fasting. These data, together with our earlier demonstration of diminished hepatic $\mathrm{T}_{3}$-neogenesis in experimental diabetes and its reversal by insulin, strongly suggested that in the rat the hepatic generation of $T_{3}$ from $T_{4}$ is closely linked to the rate of glucose utilization. This, in turn, provided a clue to the nature of the abnormality in liver cytosol produced by fasting. Our attention was directed to the role of NADPH because the activity of the hexosemonophosphate shunt, and hence the rate of the NADP reduction, is markedly impaired by fasting (46). Moreover, NADPH serves as a donor of hydrogen in several reductive syntheses, such as lipogenesis (47) and A-ring reduction of corticosteroids $(48,49)$, and 5 '-monodeiodination of $\mathrm{T}_{4}$ is also a reductive process involving substitution of hydrogen for iodine in the phenolic ring of the $T_{4}$ molecule. Most importantly, the concentration of NADPH has been shown to be reduced in the liver of fasted rats (46). As might be expected from these considerations, addition of an NADPH-generating system to hepatic cytosol from fasted animals restored the supporting activity with respect to $T_{3}$-neogenesis to a level comparable to that

\footnotetext{
${ }^{6}$ Balsam, A., F. Sexton, and S H. Ingbar. Unpublished observations.
} 
of cytosol from fed animals, regardless of the nutritional state of the donor of hepatic microsomes. ${ }^{7}$

Several studies have indicated that compounds containing reduced sulfhydryl groups, such as GSH and dithiothreitol, are stimulatory to $T_{3}$-neogenesis $(41,42$, $44,50,51)$, a finding that we have presently confirmed with respect to liver. Inasmuch as fasting decreases the hepatic GSH concentration in rats $(50,52,53)$, we would suggest that a lowering of cytosolic GSH is a second abnormality responsible for decreased $\mathrm{T}_{3}$-neogenesis in the liver of fasted animals. Consistent with this suggestion is the observation that the impaired supporting activity of cytosol from fasted rats was restored to normal by the addition of physiological concentrations of GSH. Hence, it appears that with respect to $T_{3}$-neogenesis, there are two factors deficient in the hepatic cytosol of fasted rats, NADPH and GSH. It seems likely, in addition, that the two abnormalities are at least partly related because NADPH is the cofactor in the reduction of GSSG by the enzyme, glutathione reductase. This suggestion is consonant with our finding that NADPH acted only in the presence of cytosol, whereas GSH acted not only in the presence of cytosol, but also when added directly to buffer.

Activity of the microsomal enzyme incubated in buffer was seemingly unaffected by the addition of diamide. Although this conclusion must be considered tentative because of the low activity of microsomes in buffer alone, this finding would suggest that the 5 '-monodeiodinase does not depend upon intact sulfhydryl groups within its molecule. If that is indeed the case, then the remarkable direct stimulation of $\mathrm{T}_{3}$-neogenesis by microsomes in buffer that GSH produces cannot be ascribed to reduction of intramolecular sulfhydryl groups; it suggests instead that the enzyme may act as a GSH transhydrogenase, analogous to that involved in the metabolism of insulin $(54,55)$.

\section{ACKNOWLEDGMENTS}

Data analysis was performed, in part, on the PROPHET System, a national computer resource sponsored by the Chemical/Biological Information Handling Program, National Institutes of Health.

This work was supported in part by research grant AM-18416 from the National Institute of Arthritis, Metabolism, and

${ }^{7}$ Although NADPH did reduce the extent of $T_{3}$ degradation under conditions in which it enhanced net $T_{3}$-neogenesis, the former effect was not sufficient in itself to explain the latter. Thus, when added to cytosol from fasted animals, NADPH increased $T_{3}$-neogenesis by approximately half. Under similar incubation conditions, the mean percent of ${ }^{125} \mathrm{I}_{-} \mathrm{T}_{3}$ that remained undegraded was increased by NADPH only from 96.7 to $97.9 \%$.
Digestive Diseases, and by grant RR-01032 from the General Clinical Research Centers Program of the Division of Research Resources, National Institutes of Health.

\section{REFERENCES}

1. Braverman, L. E., S. H. Ingbar, and K. Sterling. 1970. Conversion of thyroxine $\left(\mathrm{T}_{4}\right)$ to triiodothyronine $\left(\mathrm{T}_{3}\right)$ in athyreotic human subjects. J. Clin. Invest. 49: 855-864.

2. Pittman, C. S., J. B. Chambers, Jr., and V. H. Read. 1971. The extrathyroidal conversion rate of thyroxine to triiodothyronine in normal man. J. Clin. Invest. 50: 1187-1196.

3. Surks, M. I., A. R. Schadlow, J. M. Stock, and J. H. Oppenheimer. 1973. Determination of iodothyronine absorption and conversion of L-thyroxine $\left(\mathrm{T}_{4}\right)$ to L-triiodothyronine $\left(\mathrm{T}_{3}\right)$ using turnover rate techniques. J. Clin. Invest. 52: 805-811.

4. Inada, M., K. Kasagi, S. Kurata, Y. Kazama, H. Takayama, K. Torizuka, M. Fukase, and T. Soma. 1975. Estimation of thyroxine and triiodothyronine distribution and of the conversion rate of thyroxine to triiodothyronine in man. J. Clin. Invest. 55: 1337-1348.

5. Chopra, I. J. 1976. An assessment of daily production and significance of thyroidal secretion of $3,3^{\prime}, 5^{\prime}$-triiodothyronine (reverse $\mathrm{T}_{3}$ ) in man. J. Clin. Invest. 58: 32-40.

6. Money, W. L., S. Kumar, R. W. Rawson, and R. L. Kroc. 1960. Comparative effects of thyroxine analogues in experimental animals. Ann. N. Y. Acad. Sci. 86: 512-544.

7. Barker, S. B., M. Shimada, and M. Makuichi. 1965. Metabolic and cardiac responses to thyroxine analogs. Endocrinology. 76: 115-121.

8. Portnay, G. I., J. T. O'Brian, J. Bush, A. G. Vagenakis, F. Azizi, R. A. Arky, S. H. Ingbar, and L. E. Braverman. 1974. The effect of starvation on the concentration and binding of thyroxine and triiodothyronine in serum and on the response to TRH. J. Clin. Endocrinol. Metab. 39: 191-194.

9. Vagenakis, A. G., A. Burger, G. I. Portnay, M. Rudolph, J. T. O'Brian, F. Azizi, R. A. Arky, P. Nicod, S. H. Ingbar, and L. E. Braverman. 1975. Diversion of peripheral thyroxine metabolism from activating to inactivating pathways during complete fasting. J. Clin. Endocrinol. Metab. 41: 191-194.

10. Chopra, I. J., and S. R. Smith. 1975. Circulating thyroid hormones in adult patients with protein-calorie malnutrition. J. Clin. Endocrinol. Metab. 40: 221-227.

11. Spaulding, S. W., I. J. Chopra, R. S. Sherwin, and S. S. Lyall. 1976. Effect of caloric restriction and dietary composition on serum $\mathrm{T}_{3}$ and reverse $\mathrm{T}_{3}$ in man. J. Clin. Endocrinol. Metab. 42: 197-200.

12. Suda, A. K., C. S. Pittman, T. Shimizu, and J. B. Chambers, Jr. 1978. The production and metabolism of $3,5,3^{\prime}$ triiodothyronine and $3,3^{\prime}, 5^{\prime}$-triiodothyronine in normal and fasting subjects. J. Clin. Endocrinol. Metab. 47: 1311-1319.

13. Naeije, R., N. Clumeck, G. Somers, L. Vanhaelst, and J. Golstein. 1976. Thyroid hormones in serious nonthyroidal illness. Lancet. I: 1070-1071.

14. Piroska, E., and J. Foldes. 1976. Thyroid hormones in serious non-thyroidal illness. Lancet. I: 1071.

15. Suda, A. K., C. S. Pittman, J. B. Chambers, and G. Y. Ray. 1978. The etiology of the "low $T_{3}$ syndrome" and dietary therapy. Program of the 60th Meeting of the Endocrine Society, Miami, Fla. 112.

16. Burr, W. A., E. G. Black, R. S. Griffiths, R. Hoffenberg, 
H. Meinhold, and K. W. Wenzel. 1975. Serum triiodothyronine and reverse triiodothyronine concentrations after surgical operation. Lancet. II: 1277-1279.

17. Brandt, M., H. Kehlet, J. M. Hansen, and L. Skovsted. 1976. Serum triiodothyronine and surgery. Lancet. I: 491.

18. Carter, J. N., C. J. Eastman, J. M. Corcoran, and L. Lazarus. 1974. Effect of severe chronic illness on thyroid function. Lancet. II: 971-974.

19. Bermudez, F., M. I. Surks, and J. H. Oppenheimer. 1975. High incidence of decreased serum triiodothyronine concentration in patients with nonthyroidal disease. J. Clin. Endocrinol. Metab. 41: 27-39.

20. Chopra, I. J., U. Chopra, S. R. Smith, M. Reza, and D. H. Solomon. 1975. Reciprocal changes in serum concentrations of $3,3^{\prime}, 5^{\prime}$-triiodothyronine (reverse $\mathrm{T}_{3}$ ) and 3,3',5-triiodothyronine $\left(\mathrm{T}_{3}\right)$ in systemic illnesses. J. Clin. Endocrinol. Metab. 41: 1043-1049.

21. Chopra, I. J., D. H. Solomon, U. Chopra, R. T. Young, and G. N. Chua Teco. 1974. Alterations in circulating thyroid hormones and thyrotropin in hepatic cirrhosis: evidence for euthyroidism despite subnormal serum triiodothyronine. J. Clin. Endocrinol. Metab. 39: 501-511.

22. Nomura, S., C. S. Pittman, J. B. Chambers, Jr., M. W. Buck, and T. Shimizu. 1975. Reduced peripheral conversion of thyroxine to triiodothyronine in patients with hepatic cirrhosis. J. Clin. Invest. 56: 643-652.

23. Saberi, M., F. H. Sterling, and R. D. Utiger. 1975. Reduction in extrathyroidal triiodothyronine production by propylthiouracil in man. J. Clin. Invest. 55: 218-223.

24. Geffner, D. L., M. Azukizawa, and J. Hershman. 1975. Propylthiouracil blocks extrathyroidal conversion of thyroxine to triiodothyronine and augments thyrotropin secretion in man. J. Clin. Invest. 55: 224-229.

25. Duick, D. S., D. W. Warren, J. T. Nicoloff, C. L. Otis, and M. S. Croxson. 1974. Effect of single dose dexamethasone on the concentration of serum triiodothyronine in man. J. Clin. Endocrinol. Metab. 39: 1151-1154.

26. Chopra, I. J., D. E. Williams, J. Orgiazzi, and D. H. Solomon. 1975. Opposite effects of dexamethasone on serum concentrations of $3,3^{\prime}, 5^{\prime}$-triiodothyronine (reverse $\mathrm{T}_{3}$ ) and 3,3',5-triiodothyronine $\left(\mathrm{T}_{3}\right)$. J. Clin. Endocrinol. Metab. 41: 911-920.

27. DeGroot, L. J., and K. Hoye. 1976. Dexamethasone suppression of serum $\mathrm{T}_{3}$ and $\mathrm{T}_{4} . J$. Clin. Endocrinol. Metab. 42: 976-978.

28. Burgi, H., C. Wimpfheimer, A. Burger, W. Zaunbauer, H. Rosler, and T. LeMarchand Beraud. 1976. Changes of circulating thyroxine, triiodothyronine, and reverse triiodothyronine after radiographic contrast agents. J. Clin. Endocrinol. Metab. 43: 1203-1210.

29. Wu, S. Y., I. J. Chopra, D. H. Solomon, and L. R. Bennett. 1978. Changes in circulating iodothyronines in euthyroid and hyperthyroid subjects given ipodate (oragrafin), an agent for oral cholecystography. J. Clin. Endocrinol. Metab. 46: 691-697.

30. Wiersinga, W. M., and J. L. Touber. 1977. The influence of $\beta$-adrenoreceptor blocking agents on plasma thyroxine and triiodothyronine. J. Clin. Endocrinol. Metab. 45: 293-298.

31. Burger, A., D. Dinichert, P. Nicod, M. Jenny, T. LeMarchand-Beraud, and M. B. Valloton. 1976. Effect of amiodarone on serum triiodothyronine, reverse triiodothyronine, thyroxin, and thyrotropin: a drug influencing peripheral metabolism of thyroid hormone.J. Clin. Invest. 58: 255-259.

32. Eisenstein, Z., S. Hagg, A. G. Vagenakis, S. L. Fang,
B. Ransil, A. Burger, A. Balsam, L. E. Braverman, and S. H. Ingbar. 1978. Effect of starvation on the production and peripheral metabolism of 3,3',5'-triiodothyronine in euthyroid obese subjects. J. Clin. Endocrinol. Metab. 47: 889-893.

33. Balsam, A., S. H. Ingbar, and F. Sexton. 1978. The influence of fasting diabetes and several pharmacological agents on the pathways of thyroxine metabolism in rat liver. J. Clin. Invest. 62: 415-424.

34. Balsam, A., S. H. Ingbar. 1977. On the mechanism of inhibition of triiodothyronine $\left(\mathrm{T}_{3}\right)$ generation from thyroxine $\left(\mathrm{T}_{4}\right)$ by fasting and hypothyroidism. (Abstract) Proceedings of the 53rd Meeting of the American Thyroid Association, Cleveland, Ohio. T-13.

35. Balsam, A., and S. H. Ingbar. 1978. The mechanism of regulation of triiodothyronine $\left(\mathrm{T}_{3}\right)$ generation from thyroxine $\left(\mathrm{T}_{4}\right)$ in liver of normal and fasted rats. Clin. Res. 26: 489A. (Abstr.)

36. Balsam, A., F. Sexton, and S. H. Ingbar. 1978. The effect of thyroidectomy, hypophysectomy, and hormone replacement on the formation of triiodothyronine from thyroxine in rat liver and kidney. Endocrinology. 103: 17591767.

37. Harris, A., S. Fang, L. Braverman, and A. Vagenakis. 1977. Effect of carbohydrate, protein and fat infusion on hepatic $\mathrm{T}_{3}$ generation in the fasted rat. (Abstract) Proceedings of the 53rd Meeting of the American Thyroid Association, Cleveland, Ohio. T-13. (Abstr.)

38. Kaplan, M. M., and R. D. Utiger. 1978. Iodothyronine metabolism in rat liver homogenates. J. Clin. Invest. 61: 459-471.

39. Lowry, O. H., N. J. Rosebrough, A. L. Farr, and R. J. Randall. 1951. Protein measurement with the Folin phenol reagent. J. Biol. Chem. 193: 265-275.

40. Dunnett, C. W. 1970. Multiple comparisons. In Statistics in Endocrinology. J. W. McArthur and T. Colton, editors. The M.I.T. Press, Cambridge, Mass. 1: 86-87.

41. Chopra, I. J. 1978. Sulfhydryl groups and the monodeiodination of thyroxine to triiodothyronine. Science (Wash. D. C.). 199: 904-906.

42. Visser, T. J., F. Vander Does-Tobe, R. Doctor, and G. Hennemann. 1976. Subcellular localization of a rat liver enzyme converting thyroxine into triiodothyronine and possible involvement of essential thiol groups. Biochem. J. 157: 479-482.

43. Hoffken, B., R. Kodding, A. Von Zur Muhlen, T. Hehrmann, H. Juppner, and R. D. Hesch. 1977. Regulation of thyroid hormone metabolism in rat liver fractions. Biochim. Biophys. Acta. 539: 114-124.

44. Kaplan, M. M. 1979. Subcellular alterations causing reduced hepatic thyoxine- 5 '-monodeiodinase activity in fasted rats. Endocrinology. 104: 58-64.

45. Kosower, N. S., E. M. Kosower, and B. Wertheim. 1969. Diamide, a new reagent for the intracellular oxidation of glutathione to the disulfide. Biochem. Biophys. Res. Commun. 37: 593-596.

46. Potter, V. R., and T. Ono. 1961. Enzyme patterns in rat liver and Morris hepatoma 5123 during metabolic transition. Cold Spring Harbor Symp. Quant. Biol. 26: 355-362.

47. Tepperman, H. M., and J. Tepperman. 1958. The hexosemonophosphate shunt and adaptive hyperlipogenesis. Diabetes. 7: 478-485.

48. Tomkins, G. M. 1957. The enzymatic reduction of $\Delta^{4}$-3-ketosteroids. J. Biol. Chem. 225: 13-24. 
49. McGuire, J. S., and G. M. Tomkins. 1959. The multiplicity and specificity of $\Delta^{4}$-3-ketosteroid hydrogenases (5a). Arch. Biochem. Biophys. 82: 476-477.

50. Harris, A., S. Fang, L. Braverman, and A. Vagenakis. 1978. Role of sulfhydryl groups $(\mathrm{SH})$ on the impaired hepatic $\mathrm{T}_{3}$ generation from $\mathrm{T}_{4}$ in the hypothyroid, starved, fetal and neonatal rodent. Clin. Res. 26: 491A. (Abstr.)

51. Leonard, J. L., and I. N. Rosenberg. 1978. Thyroxine 5 '-deiodinase activity of rat kidney: observations on activation by thiols and inhibition by propylthiouracil. Endocrinology. 103: 2137-2144.

52. Maruyama, E., K. Kojima, T. Higashi, and Y. Sakamoto.
1968. Effect of diet on liver glutathione and glutathione reductase. J. Biochem. (Tokyo). 63: 398-399.

53. Jaeger, R. J., R. B. Conolly, and S. D. Murphy. 1974. Effect of $18 \mathrm{hr}$ fast and glutathione depletion on 1,1dichloroethylene-induced hepatotoxicity and lethality in rats. Exp. Mol. Pathol. 20: 187-198.

54. Narahara, H. T., H. H. Tomizawa, and R. H. Williams. 1956. Sulfhydryl factors in degradation of insulin- $I^{131}$ by liver extracts. Proc. Soc. Exp. Biol. Med. 92: 718-721.

55. Tomizawa, H. H. 1962. Mode of action of an insulindegrading enzyme from beef liver. J. Biol. Chem. 237: 428-431. 